\title{
Making Virtual Learning Environments Accessible to People with Disabilities in Universities in Uganda
}

\author{
Rehema Baguma $^{1 *}$ and Maria K. Wolters ${ }^{2}$ \\ ${ }^{1}$ School of Computing and IT, College of Computing and IT, Makerere University, Kampala, Uganda, ${ }^{2}$ School of Informatics, \\ Institute for Design Informatics, University of Edinburgh, Edinburgh, United Kigdom
}

Public and private universities in Uganda have been using Virtual Learning Environments (VLEs) since early 2000s to support delivery of blended learning owing to the increased uptake of technology in many aspects of life, and the benefits of blended learning/ eLearning. eLearning is of particular benefit to people with disabilities, since they may find it difficult to attend classes on a university campus. Accessibility of a VLE has a strong impact on user engagement and adoption and consequently on students' learning outcomes. Current research on use of VLEs and eLearning in general in Ugandan universities focuses on sensitization and training, the potential of social media like WhatsApp and Facebook, and required resources like Internet connectivity, and change management. In stark contrast, there is no investigation of accessibility to people with disabilities, even though about $12.4 \%$ of the population have some form of disability. This paper examines the extent to which Uganda's policy environment promotes making eLearning accessible, reviews the accessibility of a sample of VLEs of public and private universities in Uganda, and suggests recommendations on

OPEN ACCESS

Edited by: Carlos Duarte

University of Lisbon, Portugal

Reviewed by:

Claire Kearney-Volpe,

New York University, United States

Mike Kent,

Curtin University, Australia

${ }^{*}$ Correspondence:

Rehema Baguma

rehema.baguma@gmail.com

Received: 05 December 2020 Accepted: 20 April 2021

Published: 16 June 2021

Citation:

Baguma $R$ and Wolters MK (2021) Making Virtual Learning Environments Accessible to People with Disabilities in Universities in Uganda.

Front. Comput. Sci. 3:638275 doi: 10.3389/fcomp.2021.638275 addressing the existing accessibility gaps in policy and implementation of VLEs.

Keywords: virtual learning environment, learning management system, elearning, accessibility, people with disabilities, higher education institutions, Uganda

\section{INTRODUCTION}

As part of the ongoing Covid-19 lockdown, all tertiary institutions across Uganda were required to shift to Open Distance and eLearning (ODeL). Before an institution can be cleared to offer remote teaching and learning, they need to show that they adhere to guidelines that were issued in July 2020 by the National Council for Higher Education (NCHE). One of the requirements is an interactive learning management system (LMS) that effectively supports eLearning, which should provide for student-to-student interactions; student and instructor interactions, and evaluation of interaction. However, institutions are not required to ensure that all remote learning activities, and in particular the LMS and its content, are accessible to students with disabilities, even though $12.4 \%$ of the population have a disability (National Population and Housing Census, 2014).

Following the UN (Convention on the Rights of Persons with Disabilities (CRPD), 2020), we define people with disabilities as those who have long-term impairments that make it difficult for them to fully and effectively participate in society on an equal footing with others (Article 1). These impairments can be sensory, physical, mental, or cognitive. Our use of the term "people with disabilities" follows the recommendations in Hanson et al. (2015) and echoes the particular terminology and person-first language used in many relevant legal and policy documents. We 
recognize, however, that terms such as disability and impairment are inherently problematic and will return to this in Section Discussion.

The 2014 Uganda National Population and Housing Census defined disability prevalence as the proportion of the population aged two years and above who had difficulty in seeing, walking, hearing or remembering (National Population and Housing Census, 2014). In order to ensure that those with disabilities can access higher education, strong laws and policies that promote inclusive education need to be in place. Article 24 of the UN (Convention on the Rights of Persons with Disabilities (CRPD), 2020) defines inclusion as a process of systemic reform embodying changes and modifications in content, teaching methods, approaches, structures and strategies in education to overcome barriers with a vision serving to provide all students of the relevant age range with an equitable and participatory learning experience and environment that best corresponds to their requirements and preferences."

This paper examines the extent to which Uganda's policy environment promotes inclusive ODeL, reviews the extent VLEs of selected public and private universities in Uganda are currently accessible to people with disabilities, and suggests recommendations on how existing gaps in policy and implementation of VLEs can be addressed to improve the accessibility of VLEs of universities in Uganda.

\section{BACKGROUND}

\section{Accessible eLearning}

Guglielman (2010) categorized eLearning accessibility into technological and pedagogical accessibility. Technological accessibility includes the accessibility of hardware and software, adaptive and assistive technology, websites, and eLearning platforms covering both the static and configurable design. On the other hand, pedagogical accessibility involves access to content, resources, and documents, interaction and collaboration tools such as chats, forums, Wikis; and access to learning activities like labs, group work, peer practices, quizzes, projects, debates, etc. Making content accessible involves being able to read text, convert content into another format and download content in different formats such as Doc, PDF, audio and video.

Virtual Learning Environments (VLEs) are software packages through which learning activities are delivered online in the context of eLearning or blended learning. To-date, there are close to 200 VLEs on the market and more than half of these are open source (Hersh, 2008). Presently, Moodle is the most widely used open source VLE around the world (Medevel.com). VLEs should be accessible to all learners, including those with disabilities, to support an inclusive educational experience. Accessibility of a VLE should cover all student, administrator, and teacher functions, including editing and content authoring, with prompts for features such as alternative text descriptions of figures/images, content and formatting of documents posted on the system, and system modification in the case of open source software (Hersh, 2008).
For VLEs to effectively facilitate learning for all categories of learners including those with disabilities, all learners must be able to find course content, participate, collaborate, communicate with the facilitator and peers, and complete required tasks. Accessibility of a VLE has a strong impact on user engagement and adoption and consequently on students' learning outcomes. Students may fail to execute or participate in certain activities, they may fail to access or use learning resources, and they may not come back for more learning if they have not had a great experience. However, if the VLE was built with accessibility in mind, and content authors adhere to principles of accessibility, it has the potential to make higher education more accessible to everyone, particularly those with visual, hearing, and cognitive impairments (Hersh, 2008). In an accessible ODeL environment, people with disabilities have a high chance of learning better given the advantages ODeL brings to learning such as self-paced learning, ubiquitous access to learning resources, and remote collaboration, among others (Baguma, 2017). eLearning allows learners with disabilities to be more self-reliant, and to dispel the alleged misconceptions by some educators that such learners are incompetent and means that such learners no longer need to rely on other students to do their assignments (Beyene et al., 2020).

\section{eLearning in Uganda}

Makerere University and other public universities in Uganda have been using Virtual Learning Environments (VLEs) since early 2000s. Makerere University started with Blackboard in 2003 and later moved to an instance of Moodle called Makerere University eLearning Environment (MUELE). Other universities like Makerere University Business School, and Gulu University followed with Moodle (Mayoka and Kyeyune, 2012). To date, private universities have also set up VLEs to support delivery of blended learning owing to the increased uptake of technology in many aspects of life, the benefits of blended/eLearning and most recently the Covid-19 lockdown.

Moodle is designed to provide equal functionality and information to all people regardless of disabilities, assistive technologies used, different screen sizes and different input devices such as mouse, keyboard and touchscreen ${ }^{1}$. According to Rogers, the Moodle LMS incorporates best practices such as "Alt tag" text descriptions for images and figures. Students can be designated as the user of a screen reader so that page content adapts to the read-out-loud format, the interface is simplified to remove clutter, and the long lists of links can be skipped by the screen reader. Moodle is also zoom-enabled, allowing users with low vision to increase the size of content for better readability. It supports keyboard navigation which is important for users of screen readers and those with mobility limitations that prevent them from using a mouse. However, even with an accessible eLearning platform, content must still be created, organized, and formatted following accessibility best practices for an eLearning platform and its contents to be accessible to people with disabilities. On 9th November 2020, Moodle released version

${ }^{1}$ https://moodle.org/(accessed on 15th November 2020). 
3.10 and Moodle 3.9.3 in which it addressed WCAG 2.1 Level A and Level AA issues raised from an external audit that had been sanctioned earlier ${ }^{1}$. Most accessibility improvements were also back-ported to versions 3.7.5+ and 3.8.2+.

Research on use of VLEs and eLearning in general in Ugandan universities is still limited. The focus has been more on sensitization and training, required resources like Internet connectivity, and change management (Mayoka and Kyeyune, 2012). Other studies have examined the potential of emerging technologies like WhatsApp (Baguma et al., 2019) and Facebook (Bagarukayo, et al., 2016). To the best of our knowledge, this paper is the first to assess the accessibility of the VLEs of universities in Uganda, which form a core part of Ugandan students' ODeL experience, for people with disabilities.

\section{THE POLICY LANDSCAPE}

Both international and national policy instruments demand for access, equity and quality as regards educational services for persons with special learning needs. Uganda is a signatory to International Agreements on making education accessible to people with disabilities. At the national level, a number of laws and policies that promote provision of education to those with disabilities, and accessibility of ICTs and ICT enabled services, have also been developed. This section reviews key international and national policies that promote making education accessible.

\section{Existing Policy Environment Commitment to the Global Agenda}

At the global level, Uganda has committed herself to the global disability agenda. We focus on three policy documents that cover the rights of adults with disabilities: the 2030 Sustainable Development Goals (SDGs), the UN Convention on the Rights of Persons with Disabilities (CRPD), and the Marrakesh Treaty.

\section{The 2030 Sustainable Development Goals}

In September 2015, while Uganda was holding the UN presidency, the 192 member states of the UN adopted a resolution committing themselves to the 2030 Agenda for Sustainable Development. The 2030 agenda and associated 17 SDGs informs and guides global and national development. The 17 SDGs are centered on the principle of leaving no one behind, a holistic approach to achieving sustainable development for all. Throughout the 17 SDGs, disability is referenced in multiple parts, specifically related to education, growth and employment, inequality, accessibility of human settlements, as well as data collection and monitoring the SDGs (UN.org). SDG 4 states: “To ensure equitable and inclusive quality education and promote lifelong learning opportunities for all.” Specifically, target 4.5 states: "By 2030, eliminate gender disparities in education and ensure equal access to all levels of education and vocational

${ }^{1}$ https://moodle.org/(accessed on 15th November 2020). training for the vulnerable, including Persons with Disabilities (PWDs)...."

UN Convention on the Rights of Persons with Disabilities In 2018, Uganda ratified the CRPD which mandates all states to protect, respect and fulfill the right to education without discrimination. However, in a 2016 dialogue with the CRPD Committee and the Ugandan government regarding conditions for people with disabilities in Uganda, delegates from Disabled Persons Organizations noted the need to translate the CRPD into amendments to national law, including the 2006 Persons with Disabilities Act, and the need for budgetary allocations to disability programs particularly in education, health and employment (Disability Rights Fund, 2016; Uganda DPOs Present Critical Rights Issues to CRPD Committee, 2016).

\section{The Marrakesh Treaty}

The Marrakesh Treaty, adopted on June 27, 2013 in Marrakesh forms part of the body of international copyright treaties administered by The World Intellectual Property Organization (WIPO). Its main goal is to create a set of mandatory limitations and exceptions for the benefit of the blind, visually impaired, and otherwise print disabled (VIPs) through facilitating access to Published Works for the visually impaired learners (Access to Information for the Visually Impaired has been Made Possible, 2020). Uganda ratified the Treaty in 2018, and in the same year, it entered into force in the country (Afri-can.org).

\section{National Level}

At the National level, a number of laws and polices promote provision of education to people with disabilities, and accessibility of ICTs and ICT enabled services. In addition, the Education and Sports Sector Strategic Plan 2017/18 - 2019/20 earmarks promotion of eLearning and computer literacy in secondary and tertiary education in order to enhance learning outcomes. Here, we focus on those relevant to Higher Education.

\section{Rights of People with Disabilities}

The Constitution of Uganda, adopted in 1995, enshrines relevant disability rights in three articles: Article 16 recognizes the right of persons with disabilities to respect and human dignity, Article 32 outlaws discrimination on the basis of disability, and Article 34 recognizes the right of all children to benefit from education. In order to address violations of these articles, the National Council for Disability Act was passed in 2003. The rights of people with disabilities were further spelled out in the 2006 Disability Act, which promotes equal opportunities, empowerment, and participation and protects disability rights regardless of age, gender, or type of disability. The Disability Act was accompanied by a human rights-based policy framework, the 2006 National Policy on Disability.

Article 24b of the 2001 Universities and Other Tertiary Institutions Act specifically notes that all people, including those with disabilities, should have the opportunity of acquiring higher education. The Special Needs and Inclusive Education Policy (still in its 2011 draft form) promotes provision of specialized instructional materials, equipment and supportive services to all categories of learners at all levels of 
education. It also provides for training of special needs and inclusive education personnel, and guides on access to physical environment in schools, on the curriculum, and on assessment and information. However, there are no special higher education institutions for people with disabilities. Hence, they rely on support available in mainstream universities.

\section{ICT for People with Disabilities}

The Uganda Communications Act 2000 (UCC) promotes research into the development and use of new communications techniques and technologies, including those which promote accessibility of hearing-impaired people to communication services. The National IT Authority-Uganda (NITA-U) Act (2009) provided for the establishment of the National IT Authority-Uganda (NITA-U). One of the goals of NITA-U (section Evaluation of University Virtual Learning Environments for Accessibility, sub-section (f)) is to promote access to and use of ICT for youth, women, and people with disabilities. These three "special interest groups" are also highlighted in Section 4.6.1.1 of the National ICT Policy (2014-2019). A draft ICT for Disability Policy was published in 2017. It promotes sector-wide interventions to improve the lives of all Ugandans through ICT. The policy seeks to augment government efforts to promote the social economic development of people with disabilities mainly through provision of health services and special needs/inclusive education, which is to be achieved by developing and supplying accessible ICTs and ICT enabled services in Uganda.

\section{Gaps in the Policy Environment Partial Coverage of Access for People with Disabilities by ICT Policies}

Whereas Uganda boasts of an ICT regulatory framework that covers the needs of people with disabilities, the relevancy of existing ICT policies to the promotion of ICTs and ICT enabled services such as eLearning that are accessible to those with disabilities is low. In the NITA-U Act 2009, The Uganda Communications Act 2000 and the National ICT Policy 2014-2019, people with disabilities have been categorized with youth and women as a special interest group. Due to this generalization, key issues that are specific to those with disabilities, such as the use of ICT as a means to remove barriers to learning, are not highlighted. This limits the relevancy of such policy instruments to the demand for access, equity and quality to educational services. Where specific provisions are made, they are limited to specific types of disability. For example, the Uganda Communications Act 2000 only refers to promotion of accessibility of communication services to the hearing impaired. But, given the current technological and communications convergence, people with other disabilities particularly visual and learning disabilities are also affected by the telecommunication and broadcasting services regulated by the Communications Act 2000 (ICT for Disability Policy, 2017).

\section{Lack of Policies Focused on Making eLearning Accessible to People with Disabilities}

To date, there is no policy on eLearning accessibility to people with disabilities either as part of other related policies or as a standalone policy. The Special Needs and Inclusive Education policy that was drafted in 2011 has remained in draft till today, a situation the Government of Uganda attributes to lack of financial resources for its implementation (The Independent, 2019). But even this draft does not mention eLearning, much less accessible eLearning. In the absence of such policy guidance, consideration of disability-specific needs in the implementation of eLearning in higher education institutions is limited, and in most cases nonexistent. Educators and the education environment are not supported in providing eLearning that is accessible to people with disabilities. This greatly disadvantages those living with disabilities, especially given the potential benefits of eLearning to them. Similarly, the ICT and Disability Policy has been in draft form since 2017 for the same reason of inadequate resources, and makes no mention of accessible eLearning/education technology.

The 2011 draft Policy on Special Needs and Inclusive Education does not specify ICT or education technology as one of the instructional materials, equipment and supportive service. On the other hand, the 2017 second draft Policy on ICT for Disability proposes comprehensive sector-wide interventions to improve the lives of all Ugandans by facilitating and promoting the use of ICTs, but does not make reference to making eLearning accessible to people with disabilities, or to the 2011 draft Policy on Special Needs and Inclusive Education, although it came into existence when the latter had been in place albeit in draft form, for six years.

\section{DISCUSSION}

Uganda has many enabling policies and laws aimed at protecting the interests of children with disabilities and creating equal opportunities for people with disabilities (Abimanyi-Ochom and Mannan, 2014). However, there are still considerable policy gaps, and key policies such as the Policy on Special Needs and Inclusive Education and the ICT for Disability Policy, are still in draft form. Relevant officials in Government of Uganda attribute the delay to pass the policies to lack of financial resources to implement the policies once they are passed. The delay to pass and implement inclusion policies shows that Government of Uganda is yet to give inclusion issues in general, and inclusive education in particular, the priority they deserve. Lack of substantive policy instruments limits the demand for access, equity and quality to educational services. This can explain why the ODeL guidelines released by the National Council for Higher Education (NCHE) in July 2020 to guide remote teaching and learning activities during the Covid19 lockdown are silent on ensuring that all remote learning activities, and in particular the LMS and its content, are accessible to students with disabilities, despite the fact that $12.4 \%$ of the population have a disability (National Population and Housing Census, 2014). The global and national antidiscrimination laws and treaties on education and ICT must be accompanied by country-specific statutes that specify the steps that should be taken to facilitate inclusion in education and ODeL (Singal et al. 2017). It has also been noted that there is a substantial lack of data to inform policy making 
(Abimanyi-Ochom and Mannan, 2014; Wozniak et al., 2020). The implementation of the existing policy framework is weak, and resources made available to translate policies into services for people with disabilities are always insufficient (Abimanyi-Ochom and Mannan, 2014). Thus, in spite of government efforts, people with disabilities continue to face difficulties accessing quality education.

Finally, we note that the use of the term "people with disabilities" and the emphasis on impairments does not reflect the complex lived experience of those who face digital exclusion because of the way in which they perceive and interact with the world around them. In Disability Studies, this tension has been framed as a contrast between a medical and a social model of disability (see e.g., Haegele and Hodge, 2016 for a summary). The legal and policy documents we cite are strongly influenced by the medical model of disability, which sees impairments as defects to be cured. In the medical model, people with impairments are provided with assistance to function in a society designed for able-bodied people. In the social model, on the other hand, society itself should change to remove barriers to participation.

\section{EVALUATION OF UNIVERSITY VIRTUAL LEARNING ENVIRONMENTS FOR ACCESSIBILITY \\ Universities Sampled}

Uganda has 11 public and 39 private universities. We selected 3 institutions from each category. The 3 public universities covered include:

- Makerere University (MUK), founded in 1922, the oldest and biggest university in the country located in Kampala, the capital city, which has an Eastern Campus in Jinja.

- Kyambogo University (KYU), founded in 2003, which has a Faculty of Special Needs and Rehabilitation, also located in Kampala.

- Busitema University (BUS), founded in 2007, located in the eastern part of the country, which also has campuses in Mbale, Tororo, Soroti, and Kamuli Districts

The 3 private universities include:

- Uganda Technology and Management University (UTAMU), founded in 2012 and located in Kampala.

- Uganda Martyrs University (UMU), founded in 1993 and affiliated with the Roman Catholic church in Uganda, which has 10 campuses across the country with the main campus located along the Equator at Nkozi, $80 \mathrm{kms}$ west of Kampala. Around $75 \%$ of all students are enrolled in distance learning programmes.

- Kampala International University (KIU), founded in 2001, which has a main campus in Kampala, a Western campus in Ishaka, and a campus in Dar es Salaam, Tanzania.

All six universities use VLEs based on Moodle. Information about their institutional websites and websites of their VLEs is summarized in Table 1. For each University, we chose six courses from a variety of Schools, including Health, Engineering, Education, Science, and Agriculture. The selected courses are summarized in Table 2.

\section{Types of Disabilities Covered}

Our evaluation focused mostly on accessibility to people with visual, and to some extent hearing impairments, and those with motor impairments who find it difficult to use a mouse. This was due to the fact that use of digital video and audio materials in teaching and learning in Uganda is still limited, and the field of automated and manual assessment of visual accessibility has been widely studied and provides more mature tools and guidelines to use.

\section{Methodology}

\section{Automatic Accessibility Evaluation}

To assess the accessibility of the eLearning platforms under study, WAVE, a suite of evaluation tools that can identify Web Content Accessibility Guideline (WCAG) errors, but also facilitates human evaluation of web content was used. WAVE can be used online by entering the address of the website/system under evaluation at: https://wave.webaim.org/, or installing browser extensions (Firefox and Chrome) for evaluating local, dynamic, or password-protected pages and site-wide WAVE tools for easily evaluating numerous pages $^{2}$. For this study, the online option was used. WAVE reports the number and category of errors (issues that need to be fixed), alerts (potential problems that need to be checked), and good accessibility practices. In this study, we focused on errors and alerts. Table 3 provides an overview of the errors and alerts we observed, and outlines ways to address them.

The web address of each VLE studied was entered in the WAVE site at: https://wave.webaim.org/, and all errors and alerts returned were noted.

\section{Manual Accessibility Evaluation Using Heuristics From Accessibility Standards and Guidelines}

Based on international accessibility standards and guidelines such as The Web Content Accessibility Guidelines 1.0 and 2.0 (WCAG 1.0 and 2.0), eLearning accessibility principles, and VLE accessibility evaluation metrics, a set of nine accessibility principles and best practices (heuristics) were identified and subsequently used in the evaluation. Using the heuristics, the first author, who has extensive experience in web accessibility and usability, walked through the user interfaces of the six sample VLEs to identify existing accessibility problems. The nine accessibility principles and best practices (heuristics) include:

1) Appropriate alt text descriptions for graphics and rich media: Graphics play an important role in teaching, particularly in the sciences and engineering, by providing important supplementary or complementary information to the main text. Sometimes, graphical representation may be the main or sole representation of a particular content.

\footnotetext{
${ }^{2}$ https://webaim.org/(accessed on 20th October 2020).
} 
TABLE 1 | Universities whose VLEs were studied and courses evaluated.

\section{University}

Public

Makerere university (MUK)

Kyambogo university (KYU)

Busitema university (BUS)

Private

Uganda Technology and management university (UTAMU)

Uganda Martyrs university (UMU)

Kampala international university (KIU)

Main website

VLE website

https://www.mak.ac.ug/

https://kyu.ac.ug/

https://www.busitema.ac.ug/

https://utamu.ac.ug/

https://www.umu.ac.ug/

https://kiu.ac.ug/ https://muele.mak.ac.ug/login/index.php https://kelms.kyu.ac.ug/

https://lms.busitema.ac.ug/login/index.php

https://elearning.utamu.ac.ug/

https://elearning.umu.ac.ug/

https://lms.kiu.ac.ug/login/index.php

TABLE 2 | Courses evaluated.

University

Public

Makerere university (MUK)

Kyambogo university (KYU)

Busitema university (BUS)

Private

Uganda Technology and management university

(UTAMU)

Uganda Martyrs university (UMU)

Kampala international university (KIU)

\section{School}

School of computing and IT

School of public health

Faculty of education

School of management and entrepreneurship

Faculty of special needs and rehabilitation

Faculty of engineering

Faculty of health sciences

Faculty of agriculture and animal sciences

School of computing and engineering

School of business and management

Faculty of agriculture

Faculty of science in education

Faculty of science

Faculty of education

School of mathematics and computing

School of applied and natural science

\section{Courses in the VLE}

evaluated

1. Audit and security assurance principles

2. Web-based information systems and web mining technologies

1. Multimedia design for instruction

2. e-tutoring and training

1. Introduction to health care and health systems

2. Principles of public health

1. Research methodology

2. Critical discourses in education and training

1. Business finance

2. Principles of accounting

1. Community psychology

2. Computer applications in research

1. Engineering mathematics 1

2. Engineering geology

1. Principles of health communication

2. Principles of public health and disease control

1. Soil science for engineers

2. Thermodynamics

1. IT project planning and management

2. System analysis and design

3. Computer networks

1. Business finance

2. Introduction to monitoring and evaluation

3. Management information systems

1.Climatology and Field Engineering

2. Agricultural Extension Education Practical Skills

1. Discrete Mathematics

2. Entomology and Parasitology

1. Cell Biology

2. Circuit Theory

1.Selection and utilization of instructional resources

2. Principles and practices of open, distance and e-learning

1. Calculus

2. Structured programming

1. Natural resources and landscape processes

2. Aquaculture production systems
Hence, graphical material should be accessible to both the sighted and the blind or visually impaired people. VLEs that support accessibility should prompt for alternative text descriptions for figures/images. But these descriptions should provide the same type of information as that perceived by sighted users, in order to support learning for non-sighted users in the same way as the figures themselves. Cases where only figure captions instead of meaningful descriptions of the figures are provided just to meet the technical accessibility requirements are common. 
TABLE $\mathbf{3}$ | Accessibility issues and suggestions for addressing them.

\begin{tabular}{|c|c|c|}
\hline Name & Description & Suggested solution \\
\hline \multicolumn{3}{|l|}{ Errors } \\
\hline $\begin{array}{l}\text { Very low color } \\
\text { contrast }\end{array}$ & Text difficult to read for all users with low vision, especially if text is small & $\begin{array}{l}\text { Use clear default contrasts between foreground (text) and background } \\
\text { colors }\end{array}$ \\
\hline Empty link & Function of the link cannot be presented to user of screen reader & Providing text within link that describes functionality or target of the link \\
\hline Empty button & Button without descriptive text that can be read out by screen reader & $\begin{array}{l}\text { Place text content within the <button }>\text { element or give the <input }> \\
\text { element a value attribute }\end{array}$ \\
\hline $\begin{array}{l}\text { Broken ARIA } \\
\text { menu }\end{array}$ & $\begin{array}{l}\text { Accessible rich internet applications menu points to something that does } \\
\text { not exist }\end{array}$ & Check all ARIA menus for broken links \\
\hline \multicolumn{3}{|c|}{ 然 } \\
\hline $\begin{array}{l}\text { Redundant title } \\
\text { text }\end{array}$ & $\begin{array}{l}\text { The value of the title attribute should provide additional information to the } \\
\text { user when the mouse hovers over an element, not repeat the text of the } \\
\text { title element }\end{array}$ & $\begin{array}{l}\text { The title attribute should be either removed or edited to be more } \\
\text { informative }\end{array}$ \\
\hline Very small text & Text is too small to read for people with vision impairment & $\begin{array}{l}\text { Increase font size so that it can be read by people with mild to moderate } \\
\text { vision problems }\end{array}$ \\
\hline $\begin{array}{l}\text { Orphaned form } \\
\text { label }\end{array}$ & Label that is not associated with a corresponding form control & Associate lable with the correct form control or remove it if unneccessary \\
\hline $\begin{array}{l}\text { Suspicious } \\
\text { alternative text }\end{array}$ & $\begin{array}{l}\text { The alternative text for an image does not summarize the content or } \\
\text { information conveyed by the image }\end{array}$ & Make alternative text informative; avoid text such as "image of" \\
\hline Redundant links & $\begin{array}{l}\text { Adjacent links that go to the same location result in additional navigation } \\
\text { for keyboard and screen reader users }\end{array}$ & $\begin{array}{l}\text { Merge links. For example, if a product image and product name are in the } \\
\text { same link, the image can usually be given alt = "" for alternative text }\end{array}$ \\
\hline $\begin{array}{l}\text { Missing first level } \\
\text { heading }\end{array}$ & $\begin{array}{l}\text { Nearly all pages should contain a first level heading with the most } \\
\text { important heading of the page for ease of navigation }\end{array}$ & Place the top heading of the page within a $<$ h1 $>$ element \\
\hline $\begin{array}{l}\text { Skipped heading } \\
\text { level }\end{array}$ & $\begin{array}{l}\text { Headings provide document structure and facilitate keyboard navigation } \\
\text { by users of assistive technology. Skipping heading levels will confuse } \\
\text { users }\end{array}$ & $\begin{array}{l}\text { Ensure headings are used as appropriate, and without skipping heading } \\
\text { levels }\end{array}$ \\
\hline Duplicate alt text & Two images near each other have the same alternative text & $\begin{array}{l}\text { If the content of the image is already conveyed elsewhere (through text or } \\
\text { the alternative text of a nearby image), determine whether the additional } \\
\text { image is necessary. It is also possible to assign empty alternative text (alt } \\
\text { = "") }\end{array}$ \\
\hline $\begin{array}{l}\text { Suspicious link } \\
\text { text }\end{array}$ & Link text should clearly describe the destination or function of the link & Reword link text to clearly describe destination or function \\
\hline Link to PDF & $\begin{array}{l}\text { PDF documents often have accessibility issues or require a separate plug } \\
\text { in/application }\end{array}$ & $\begin{array}{l}\text { Convey information in native HTML. If that is not possible, ensure that the } \\
\text { PDF is accessible }\end{array}$ \\
\hline Link to video & Videos are often not accessible & Ensure all video content is accessible (subtitling/audio description) \\
\hline
\end{tabular}

2) Support for text-only navigation including link shortcuts, hidden links and descriptive link texts: In Moodle, this can be achieved if the student is designated as the user of a screen reader so that page content adapts to the read-out-loud format and the interface is simplified to remove clutter (Hersh, 2008). This also makes the screen reader skip long lists of links when relaying the system interface to the user.

3) Scalable fonts (text) and graphics: Designation of a student as a user of a screen reader will enable the zoom functionality which allows users to increase or decrease the size of content for better readability (Hersh, 2008). To test this functionality, the home pages of VLEs should be zoomed to $200 \%$, and the content, and layout checked to see if it has automatically adjusted to fit on the screen or if there are overlaps or disappearance of some of the content/layout elements.

4) Keyboard access to all system components: Designation of a student as a user of a screen reader will also enable keyboard navigation for the whole system which is important for users of screen readers and those with mobility limitations (Hersh, 2008). This can be tested using the Tab and ShiftTab keys to establish whether all elements of the VLE can be reached through the keyboard.
5) Organize, structure, and make content clear: Screen readers read the markup not the page presented visually in the web browser. Hence, content authors should use markup correctly to organize and identify different levels of headings: H1-H6, use the bulleted or numbered list styles to bullet content instead of hyphens or other characters; only use table markup if presenting an actual table of data instead of other purposes like styling content; use bold for importance, italic for emphasis, and blockquote for callouts or quotes instead of coloring or highlighting text to make it stand out.

6) Make content clear and discernible for users with limited vision or learning disabilities: Avoid using color on its own to distinguish or organize content, as color-blind users might have difficulty understanding it. It is also advisable to ensure sufficient contrast between visual elements.

7) Make learning content accessible: Provide learning content such as word documents, pdf documents and presentations in accessible formats.

8) Make learning activities accessible: There is need to ensure that learning activities like labs, group work, peer practices, quizzes, projects, debates among others are accessible to users of screen readers. 
TABLE 4 | Summary accessibility evaluation results for university VLEs from WAVE accessibility evaluation tool.

\section{University}

Makerere university (mak)

Kyambogo university (KyU)

Busitema university (BUSU)

Uganda technology and management university (UTAMU)

Uganda martyrs university (UMU)

Kampala international university (KIU)
26

Errors

11

20

15

25

23
10

27

Alerts

22

13

22

59

\section{Details}

Errors

- 5 empty buttons

- 6 empty links

- 15 very low color contrast Alerts

- 15 orphaned form labels

- 1 skipped heading level

- 6 redundant title text

Errors

- 5 empty links

- 6 very low color contrast

Alerts

- 1 missing first level heading

- 1 skipped heading level

- 8 redundant title text

Error

- 1 empty heading

- 9 empty links

- 10 very low color contrast Alerts

- 10 suspicious alternative text

- 7 duplicate alternative text

- 4 skipped heading level

- 3 suspicious link text

- 3 link to PDF document

Errors

- 2 empty links

- 13 very low color contrast Alerts

- 2 suspicious alternative text

- 7 redundant title text

- 2 redundant links

- 1 duplicate alternative text

- 1 missing first level heading

Errors

- 10 empty buttons

- 6 empty links

- 9 very low color contrast

Alerts

- 8 redundant title text

- 12 orphaned form labels

- 2 skipped heading level

Errors

- 7 very low color contrast

- 1 empty link

- 3 broken ARIA menu

Alerts

- 28 very small text

- 11 redundant title text

- 10 redundant links

- 2 insufficient alternative text

- 2 suspicious link text

- 1 missing first level heading

- 1 embedded or linked video

(Continued on following page) 
TABLE 4 | (Continued) Summary accessibility evaluation results for university VLEs from WAVE accessibility evaluation tool.

\begin{tabular}{|c|c|c|c|}
\hline University & Errors & Alerts & Details \\
\hline Total & 110 & 157 & $\begin{array}{l}\text { Errors } \\
\text { - } 55 \text { very low color contrast (60\%) } \\
\text { - } 28 \text { empty link ( } 25 \%) \\
\text { - } 15 \text { empty button (14\%) } \\
\text { - } 3 \text { broken ARIA menu (3\%) } \\
\text { Alerts } \\
\text { - } 49 \text { redundant title text ( } 31 \%) \\
\text { - } 28 \text { very small text ( } 18 \%) \\
\text { - } 27 \text { orphaned form label }(17 \%) \\
\text { - } 15 \text { suspicious alternative text (10\%) } \\
\text { - } 13 \text { redundant links ( } 8 \%) \\
\text { - } 12 \text { missing first level heading ( } 8 \%) \\
\text { - } 8 \text { duplicate alt text (5\%) } \\
\text { - } 7 \text { suspicious link text (4\%) } \\
\text { - } 3 \text { link to PDF document (2\%) } \\
\text { - } 1 \text { embedded or linked video (<1\%) }\end{array}$ \\
\hline
\end{tabular}

9) Ensure that interaction and collaboration tools such as chats, forums, and wikis are accessible to users of screen readers.

\section{Results}

\section{Automatic Evaluation}

Detailed results are presented in Table 4 in the Supplementary Materials section. Overall, there were more alerts $(\mathrm{N}=157)$ reported than errors $(\mathrm{N}=110)$. The low number of outright accessibility problems (errors) could be due to the fact that all the studied VLEs use Moodle which has inbuilt accessibility features such as zoom which enables users to increase the size of content for better readability, and support for keyboard navigation. Nevertheless, the alerts also need to be analyzed and those found a potential problem fixed to improve the accessibility of VLEs to people with disabilities.

\section{Errors $(N=110)$}

The most frequent error, low contrast between foreground and background colours $(\mathrm{n}=60,55 \%)$, affects both users with low vision and users with normal vision who are reading the screen under adverse conditions, such as glare from the Sun. The remaining errors (empty link, $\mathrm{n}=28,25 \%$; empty button $(\mathrm{n}=$ $15,14 \%)$; broken ARIA menu $(\mathrm{n}=3,3 \%)$ ) mainly affect screen reader users, because information that screen readers require to help users navigate is not provided. Low contrast issues can be addressed by providing course content creators with welldesigned course templates, but the other three types of issues require course content creators to perform checks on the material they create.

Of particular interest are the broken ARIA menus. Accessible Rich Internet Applications (ARIA) is a set of attributes that define ways to make web content and web applications, especially those developed with JavaScript, more accessible to those with disabilities $^{3}$. It supplements HTML to ensure interactions and

${ }^{3}$ https://www.mozilla.org/en-US/(accessed on 20th October 2020). commonly used widgets can be passed to assistive technologies. For example, for forms, sometimes there is additional information beyond the <label> tag that the user needs to understand, such as a password requirement or some other requirement that is not standard. Visually, this is usually presented in additional helper text under the label. But for users of assistive technologies who navigate by form controls, adding "aria-describedby" will make the screen reader read both the label and the element that aria-describedby is pointing to (Pope, 2020). This is a good example of a case where technology to improve accessibility is provided within the system, but not used correctly.

\section{Alerts $(N=157)$}

The alerts fall into three main categories, issues that occur as part of the process of making content more accessible, issues that can be addressed by providing better templates to course creators, and issues that can be addressed by providing appropriate content design guidance.

Three of the four most frequent issues, redundant title text ( $\mathrm{n}$ $=49,31 \%)$, orphaned form labels $(\mathrm{n}=27,17 \%)$, and suspicious alternative text that does not properly describe the image it refers to $(\mathrm{n}=15,10 \%)$, can be viewed as issues that occur during the part of the process where accessibility information is added. If two images near each other have the same alternative text (Duplicate alt text, $\mathrm{n}=8,5 \%$ ), this is a sign that either one of them should be eliminated, or the textual descriuptions need to be refined. In addition, all linked videos $(\mathrm{n}=1,<1 \%)$ and PDF documents $(\mathrm{n}=$ $3,2 \%$ ) should be checked for accessibility.

The second most frequent alert, very small text $(n=28,18 \%)$, is closely linked to the most frequent error, low color contrast. The easiest remedy for this issue is to provide templates that specify an acceptable minimum text size, such as $14 \mathrm{pt}$.

The majority of the remaining issues regard content design, and will benefit all students, regardless of whether they have a disability. Text should be clearly structured, with a top level heading (missing first level heading, $\mathrm{n}=12,8 \%$ ), and a logical sequence of subheadings, where no heading levels are skipped 
TABLE 5 | Summary Results from Expert Evaluation using Heuristics.

\begin{tabular}{cccccc}
\multicolumn{7}{c}{ VLEs } \\
Makerere & Kyambogo & Busitema & UTAMU & UMU & KIU \\
No & No & No & Yes & No & No \\
No & No & No & No & No & No \\
Yes & Yes & No & Yes & Yes & Yes \\
Yes & No & No & No & No & No \\
No & No & No & No & No & No \\
Yes & Yes & Yes & Yes & Yes & Yes \\
No & No & No & No & No & No \\
Yes & Yes & Yes & Yes & Yes & Yes \\
& & & & & \\
Yes & No & No & No & No & No
\end{tabular}

Appropriate alt text descriptions for graphics and rich media

Support for text-only navigation, including link shortcuts, hidden links and descriptive link texts Scalable fonts (text) and graphics

Keyboard access to all system components

Organize, structure, and make content clear for screen reader users

Make content clear and discernible for users with limited vision or learning disabilities

Provide learning content in accessible formats

Interaction and collaboration tools such as chats, forums, and wikis that are accessible to users of screen readers

Learning activities like labs, group work, quizzes, projects, debates that are accessible to users of screen readers

Yes

No

No

No No

(skipped heading level, $\mathrm{n}=8,5 \%$ ). Where adjacent links go to the same location (Redundant links, $\mathrm{n}=13,8 \%$ ), for example a linked product image and an adjacent linked product name, content authors should choose one anchor, preferably the text, which should be automatically highlighted as a link by the style sheet. In general, a link should be associated with text that describes clearly he function or destination of the link (suspicious link text, $\mathrm{n}$ $=7,4 \%)$.

\section{Manual Evaluation}

The results of the Manual Evaluation are summarized in Table 5 in the Supplementary Materials section. All the 6 VLEs had clear and discernible content for users with limited vision or learning disabilities. The interaction and collaboration tools such as chats, forums, and wikis for all the VLEs evaluated were also accessible to users of screen readers due to Moodle's accessible interface.

All the six VLEs had scalable fonts (text) and graphics. Five of the six VLEs did not have appropriate alt text descriptions for graphics and rich media. Only the VLE of UTAMU had appropriate alt text descriptions for graphics and rich media, and only the VLE of Makerere University had keyboard access to all system components. Keyboard access was a problem for the Kyambogo University VLE due to use of frames. Although keyboard navigation could reach every function in the VLE of UTAMU, the order of presentation was not chronological. From the top, the tab key jumped to the middle section of the page, then to the right section, next was the left side, and finally the bottom part. Such a presentation of the interface is confusing to a nonvisual user relying on a screen reader. Keyboard access was not possible for the VLEs of Busitema, UMU and KIU.

None of the VLEs supported text-only navigation. In all the VLEs, the reader view was not available, which just like the screen reader removes all the extra items on the page and centers the text and images in the article for better readability. This might have been done so that users do not miss advertisements on the platforms. In addition, none of the 6 VLEs had organized, structured, and made content clear for screen reader users, and none provided learning content in accessible formats.
There were inaccessible pdfs and presentation files, and videos without synchronized captions.

\section{Discussion}

We conducted automatic and manual evaluations for the VLEs of six Ugandan universities, three public, and three private. Most of these universities have their main campus in the capital, Kampala, but four out of the six have satellite campuses across the country. All universities adopted Moodle as their VLE.

The automatic evaluation found a substantial number of errors and alerts mostly related to content while the potential accessibility barriers established from the manual evaluation were mainly platform related. Out of the four categories of errors established from automatic evaluation, three were content related namely: very low contrast, empty links, and empty buttons. The three were also the most frequent errors. The fourth type of error, i.e. broken aria menu, was associated to both platform and content accessibility and had the lowest frequency. The eLearning platform needs the "aria-described by" attribute to make the screen reader read both the label and the element that "aria-describedby" is pointing to (additional helper text). But also content authors should ensure that the additional helper text under the label passes on the same message to visual interfaces and users of screen readers. The platform should include a prompt for provision of functionality/information about each form control to the user, while the content author should provide functionality/information about each form control that communicates the same message to visual and screen reader users.

From the manual evaluation, two of the five potential accessibility barriers detected were platform related namely: lack of support for keyboard only access, and lack of support for text-only navigation while the other three were content related namely: lack of appropriate alt text descriptions for graphics and rich media, content that is not organized, structured, and clear for screen reader users, and learning content in inaccessible formats.

There were four main sources of problems in the parts of the VLEs we investigated-perceptual difficulties, lack of sufficient alternative text for users of screen readers, challenges navigating 
the VLEs and inaccessible learning content. Perceptual difficulties were mostly due to low color contrast, and small font sizes, which make it hard or impossible for people with low vision to read the text. Lack of sufficient alternative information for screen readers was pervasive and ranged from uninformative link text, to missing alternative image/figure descriptions. Challenges navigating the VLEs ranged from lack of support for keyboard and text only navigation, redundant links, duplicate alternative text, missed first level headings, skipped heading levels, and poor content structuring. Also, the learning content provided in the VLEs was in inaccessible formats such as PDFs and PowerPoint presentations that were not optimised for accessibility, and videos without synchronised captions. We believe that a number of accessibility gaps are due to non-consideration of accessibility during configuration, use and administration of the VLEs given the vacuum in the regulatory environment in the country.

For example, Moodle options that easily support screen readers, such as reader view, are not enabled.

While most of our findings related to presentation of visual information, the manual evaluation also uncovered issues with content structuring, which supports people with cognitive difficulties.

The accessibility gaps established in the studied VLEs pose a big barrier to meaningful eLearning for people with disabilities. Our analysis methodology focused mostly on accessibility for those with visual impairments, screen reader users, those with hearing impairment, and those with motor impairments that make it difficult to use a mouse.

Adequate contrast between text and background color is necessary for all users but in particular for users with low vision especially for content presented in small text (less than 14 point), Lack of or inappropriate text description for links, buttons, form controls, aria menus, images or figures introduces confusion for screen reader users because the function or purpose of those elements will not be known. If the alternative text for an image does not provide the same information conveyed by the image, that content will not be available to screen reader users. Adjacent links that go to the same location like a linked product image and a linked product name for the same product results into additional navigation and repetition for keyboard and screen reader users. Similarly, two images with the same alternative text, causes redundancy or indicates incorrect alternative text which confuses users of screen readers. When heading levels are skipped, keyboard users including users of screen readers get confused or find difficulty navigating the site because headings provide the semantic structure of the document. Unless authored with accessibility in mind, PDF, Word and PowerPoint documents often have accessibility issues. Also, such documents are typically viewed using a separate application, and can thus cause confusion and navigation difficulties. Additionally, videos without synchronized captions are inaccessible to people with hearing impairments.

The study findings show that the accessibility challenges of the studied University VLEs in Uganda are mostly content related, but a substantial number of platform accessibility barriers particularly at configuration level also exist. Therefore, national policies and guidelines on inclusive education and accessible ICTs and ICT based services should emphasize awareness, training as well as monitoring and evaluation of eLearning at platform configuration and content authoring levels. The effort for accessible design of off-the-shelf eLearning platforms is driven by global human rights mandates such as the UNCRPD and the 2030 Agenda as well as global Web Accessibility standards such as WCAG 1.0 and 2.0. Hence, efforts at national level, need to focus on configuration that supports accessibility for all users including people with disabilities and accessible content authoring. Since many of the issues we uncovered will also make content more difficult to process for people without disabilities, a stronger emphasis on accessibility will ultimately make University VLEs more usable for everyone.

\section{eLearning Accessibility in Context}

Much of the literature on the accessibility of eLearning reports similar levels of problems. For example, in their evaluation of higher education websites for 20 universities across the globe, Acosta-Vargas et al. found that the majority of websites did not comply with WCAG 2.0 guidelines to an acceptable level (AcostaVargas, Luján-Mora and Salvador-Ullauri, 2016). Qualitative studies have illustrated the impact that lack of accessibility has on the experience of LMIC students (Ro'fah et al., 2020) and lecturers (Zongozzi, 2020). Ro'fah et al. note that in addition to the types of accessibility problems discussed above, students with disabilities also reported problems with contacting and obtaining support from the Disability office, which can potentially result in a vicious circle of exclusion. In interviews with lecturers from a South African ODeL institution, Zongozzi (2020) found that lecturers are well aware of the negative impact that lack of accessibility has on students with disabilities, but find it difficult to identify students who have disabilities and to provide appropriate support.

Beyene, Mekonnen and Giannoumu (2020) explored institutional problems to the accessibility of educational resources to learners with visual impairments in the Ethiopian context. They noted that lack of educational resources in alternative formats is a common problem in Higher Education Institutions (HEIs) in developing countries, and recommended sensitising teachers and university staff on the needs of students with disabilities.

\section{Limitations}

As this is the first study of accessibility for people with disabilities who study at Ugandan universities, it has several limitations of scope. First of all, we only performed a high level sample of each VLE. It is possible that individual programmes and courses at one or more of the six institutions studied would perform better or worse. Our evaluation also focused mostly on accessibility to people with visual, and to some extent hearing impairments, and those with motor impairments who find it difficult to use a mouse. This was due to the still limited use of digital video and audio materials 
in teaching and learning in Uganda, and the maturity of automated and manual assessment of visual accessibility.

\section{RECOMMENDATIONS}

\section{Policy-Level}

There is need to give more visibility to people with disabilities in ICT policies in order to cover key issues that affects them regarding use of ICTs and ICT enabled services like eLearning. People with disabilities should be made a standalone category of stakeholders in education and ICT policies instead of treating them as one of several special interest groups. In order to achieve this, people with a variety of disabilities should be closely involved in policy making.

\section{Cover all Disabilities in the Communications Act}

There is need to ensure that all disabilities affected by the accessibility of communication services are covered by the Communications Act. Relevant communication services include mass media, telecommunication, and the Internet, especially since the borders between those three types of communication channels have been significantly reduced. The convergence of media technologies and the digital forms of access and delivery offer more ways for the audiences to engage with the media (Shah, 2020), and these forms of access are extensively used in ODeL (video, podcasts, interactive presentations).

Link Existing Policy Frameworks and Create a Policy on eLearning Accessibility to People with Disabilities Currently special needs and inclusive education on one hand and ICT and disability present as two separate policy ecosystems. Given the enormous potential of ICT based learning for all learners, and given that accessible education technology is empowering and emancipating for those with disabilities, there is a clear need to link these policy ecosystems.

A relevant policy on eLearning accessibility can either be a standalone policy, or part of a related policy such as the Special Needs and Inclusive Education Policy, which is before the Ugandan Cabinet for approval. Such a policy should provide focused direction and guidance to different stakeholders on making eLearning accessible. At the minimum, the policy should address requirements by global and national disability laws, and the Web Content Accessibility Guidelines by the World Wide Web Consortium (W3C).

\section{Implementation Level \\ Teams and Action Plans}

Since eLearning design and delivery is a team effort, making eLearning accessible requires different stakeholders working together (Seale, 2006). This can be achieved by identifying representatives from key stakeholder groups namely: educators, administrators, developers, IT support team members and people with disabilities. These ambassadors can be the face of the accessibility initiative and bring attention to the progress being made. Based on the gaps in an institution's current level of eLearning accessibility, institutional action plans will be needed covering milestones, tasks, and target dates to bridge the gap. Pearson et al. (2019) suggest that Accessibility Coordinators can play an important role in the delivery of such action plans.

\section{In-House Training and Best Practice Guides}

To ensure accessibility of eLearning content, University Administrators, web developers, IT administrators, educators, student leaders and other stakeholders who play an active role in decision making in universities, developing and maintaining an accessible eLearning platform and developing eLearning content should be sensitized and trained based on their current skills and attitudes, and what actions need to be taken. This can be achieved through a combination of seminars, workshops, manuals, and eLearning courses.

In our detailed analysis of accessibility problems, we highlighted several issues that can be addressed with appropriate in-house training and best practice guidelines. A case in point are low color contrast and small font size, which can be addressed through setting an in-house style guide that mandates minimum font sizes and high color contrast options. Rogers recommends pairing all non-text content with a text alternative. This means using 'Alt tags' for images/figures to clearly describe what the image/figure depicts; videos with captions describing the audio track; audio with a text transcript; and labeling Form inputs. Provision of alternative text extends to lecture notes. For example, a student reported that some teachers include illustrations in lecture presentations and fail to thoroughly explain the illustrations, yet it is not possible to record illustrations (Beyene et al., 2020).

However, when it comes to alternative text for graphics, providing this text can be difficult. It is not enough to copy figure captions instead of providing meaningful descriptions of the figures, just to meet the technical accessibility requirements. Graphics play an important role in teaching, particularly in the sciences and engineering, by providing important supplementary or complementary information to the main text. Hersh (2008) recommends development of guidelines on what constitutes good alternative text descriptions and examples, and investigation of different types of graphics and associated learning aims to enable suggestions to be made of the different types of text description that are appropriate in each case. In addition, educational content authors should examine the role of graphics in their teaching material to ensure that learners have full access to this learning content, whether through the provision of alternative text descriptions or in some other way.

\section{CONCLUSION}

To the best of our knowledge, this is the first paper to study the accessibility of VLEs used in Ugandan Universities for people with disabilities. We found numerous accessibility issues, even though we mostly focused on accessibility to people with visual 
impairment. This is consistent with international results, even though our review of the legal and policy landscape in Uganda identified numerous issues that may be addressed in other countries. There are two areas for future work that we wish to highlight. The first area relates to coverage of impairment. The definition of disability cited earlier highlights physical and mental impairments as well as sensory disabilities, and yet our analysis focuses mostly on sensory impairments. There is a need to extend the accessibility analysis to cover the needs of people with mobility impairment (e.g., those who have lost the full use of arms, hands, or legs due to traffic accidents or illness), and people who are neurodiverse (e.g., those with autism or ADHD). The second area relates to learning design in general. Anderson (2020) noted that course design in an online environment requires pedagogical proficiency in utilizing the VLE features that promote active learning and higher order thinking skills, administrative and technical skills. As has been found repeatedly in the inclusive design literature, we would expect that good instructional design also serves to make ODeL more accessible.

\section{REFERENCES}

Abimanyi-Ochom, J., and Mannan, H. (2014). "Uganda's Disability Journey: Progress and Challenges". Afr. J. Disabil. 3 (1), 108. doi:10.4102/ajod. v3i1.108

Access to Information for the Visually Impaired has been Made Possible (2020). Available at: https://afri-can.org/access-to-information-for-the-visuallyimpaired-has-been-made-possible/ (Accessed November 10, 2020).

Acosta-Vargas, P., Luján-Mora, S., and Salvador-Ullauri, L. (2016). "Evaluation of the Web Accessibility of Higher-Education Websites". In 2016 15th International Conference on Information Technology Based Higher Education and Training (ITHET), 1-6. doi:10.1109/ithet.2016.7760703

Anderson, G. (2020). Accessibility Suffers during Pandemic. Available at: https:// www.insidehighered.com/news/2020/04/06/remote-learning-shift-leaves-studentsdisabilities-behind (Accessed October 10, 2020). doi:10.1007/s42413-02000070-X

Baguma, R. (2019). Using WhatsApp in Teaching to Develop Higher Order Thinking Skills-A Literature Review Using the Activity Theory Lens. IJEDICT 15 (2), 98-116.

Baguma, R. (2017). An Audit of Inclusive ICTs for Education in Uganda in Proceedings of ICEGOV 2017. New Delhi, India. doi:10.1145/3047273.3047339

Bagarukayo, E., Ssentamu, N. P., Mayisela, T., and Brown, C. (2016). Activity theory as a lens to understand how Facebook develops knowledge application skills. IJEDICT 2.

Beyene, W. M., Mekonnen, A. T., and Giannoumis, G. A. (2020). Inclusion, Access, and Accessibility of Educational Resources in Higher Education Institutions: Exploring the Ethiopian Context. Int. J. Inclusive Education. 0 (0), 1-17. doi:10. 1080/13603116.2020.1817580

Convention on the Rights of Persons with Disabilities (CRPD) (2020). Available at: https://www.un.org/development/desa/disabilities/convention-on-the-rights-ofpersons-with-disabilities.html (Accessed November 20, 2020).

Disability Rights Fund (2016). Available at: https://disabilityrightsfund.org/ uganda-dpos-present-critical-rights-issues-to-crpd-committee/

Education and Sports Sector Strategic Plan (2017/18 - 2019). Available at: http:// npa.go.ug/wp-content/uploads/2018/11/EDUCATION-AND-SPORTS-SECTORSTRATEGIC-PLAN.pdf (Accessed November 5, 2020).

Guglielman, E. (2010). "E-learning and Disability: Accessibility as a Contribute to Inclusion," in Proceedings of the 5th Doctoral Consortium at the European Conference on Technology Enhanced Learning, September 29, 201 (Barcelona, Spain).

\section{DATA AVAILABILITY STATEMENT}

The raw data supporting the conclusions of this article will be made available by the authors, without undue reservation.

\section{AUTHOR CONTRIBUTIONS}

$\mathrm{RB}$ conceived the original idea for the paper, conducted the policy survey and accessibility evaluation, and wrote the first full draft of the paper. MW supported RB in reshaping the original idea, conducted additional background research, and produced the final draft together with RB.

\section{FUNDING}

MW acknowledges funding from the Alan Turing Institute (EPSRC) and Lift-Health-UG. EPSRC EP/N510129/1 and Lift-Health UG GCRF/SFC Theme Development Fund TDF_20 GCRF 05.

Haegele, J. A., and Hodge, S. (2016). Disability Discourse: Overview and Critiques of the Medical and Social Models. Quest. 68 (2), 193-206. doi:10.1080/ 00336297.2016.1143849

Hanson, V. L., Cavender, A., Cavender, A., and Trewin, S. (2015). Writing about Accessibility. interactions. 22 (6), 62-65. doi:10.1145/2828432

Hersh, M. (2008). “Accessibility and Usability of Virtual Learning Environments," in the 8th IEEE International Conference on Advanced Learning Technologies, ICALT 2008, July 1st- July 5th, 2008. (Santander, Cantabria: Spain). doi:10. 1109/icalt.2008.82

ICT for Disability Policy 2nd draft 2017 (2017). Available at: https://www.ict.go.ug/ wp-content/uploads/2018/06/ICTs-for-Disability-Policy-Draft.pdf (Accessed November 2, 2020).

Mayoka, G., and Kyeyune, R. (2012). An Analysis of E-Learning Information System Adoption in Ugandan Universities. Case of Makerere University Business School. Inform. Technol. Res. J. 2 (1), 1-7.

National Population and Housing Census (2014). Available at: https://www.ubos. org/wp-content/uploads/publications/03_20182014_National_Census_Main Report.pdf.

Pearson, V., Lister, K., and Coughlan, T. (2019). “Accessibility Coordinators: A Model for Embedded, Sustainable Change towards Inclusive Higher Education". in Proceedings of the 12th Annual International Conference of Education, Research and Innovation (ICERI 2019), (Seville, Spain: IATED), 3127-3136. http://oro.open.ac.uk/68402/

Pope, J. (2020). Broken ARIA Reference - Example. https://blog.pope.tech/2020/03/ 20/broken-aria-reference-example/

Ro'fahanjarwati, A., and Suprihatiningrum, J. (2020). "Is Online Learning Accessible during COVID-19 Pandemic? Voices and Experiences of UIN Sunan Kalijaga Students with Disabilities”. Nadwa. 14 (1), 1-38. doi:10. 21580/nw.2020.14.1.5672

Seale, J. (2006). "A Contextualised Model of Accessible E-Learning Practice in Higher Education Institutions”. Australas. J. Educ. Technology. 22 (2), 268-288. doi:10.14742/ajet.1302

Shah, S. (2020). ICT: Convergence of Information and Communication Technology. Available at: https://www.sociologydiscussion.com/science/ict-convergence-ofinformation-and-communication-technology/723 (Accessed October 13, 2020). doi:10.1109/rteict49044.2020.9315618

Singal, N., Ware, H., and Bhutani, S. K. (2017). Inclusive Quality Education for Children with Disabilities. United Kingdom: University of Cambridge.

The Independent (2019). Gov't Urged to Hasten Inclusive Education Policy. Available at: https://www.independent.co.ug/govt-urged-to-hasten-inclusiveeducation-policy/ (Accessed October 2, 2020). 
Uganda DPOs Present Critical Rights Issues to CRPD Committee (2016). Available at: https://disabilityrightsfund.org/uganda-dpos-present-critical-rights-issuesto-crpd-committee/

Wozniak, S., Moses, O., and Bernard, S. (2020). "Uganda's Disability Data Landscape and the Economic Inclusion of Persons with Disabilities". Development Initiatives. Available at: https://devinit.org/resources/uganda-disability-data-landscapeeconomic-inclusion-persons-with-disabilities/. doi:10.5194/acp-2020-1070-rc1

Zongozzi, J. N. (2020). Accessible Quality Higher Education for Students with Disabilities in a South African Open Distance and E-Learning Institution: Challenges. Int. J. Disabil. Development Education 0 (0), 1-13. doi:10.1080/1034912x.2020.1822518
Conflict of Interest: The authors declare that the research was conducted in the absence of any commercial or financial relationships that could be construed as a potential conflict of interest.

Copyright $\odot 2021$ Baguma and Wolters. This is an open-access article distributed under the terms of the Creative Commons Attribution License (CC BY). The use, distribution or reproduction in other forums is permitted, provided the original author(s) and the copyright owner(s) are credited and that the original publication in this journal is cited, in accordance with accepted academic practice. No use, distribution or reproduction is permitted which does not comply with these terms. 